\title{
GLOSSARY OF MUSICAL TERMS
}

Ciaramella: a type of shawm, a double-reed woodwind instrument, mostly used together with a zampogna to play solo parts.

Organetto: a diatonic button accordion, often used as a substitute for a zampogna.

Tamburello: a frame drum, made out of a goat skin on a wooden frame, with small cymbals.

Tarantella: a folk dance typical of central and southern Italy, characterised by a fast tempo. In Basilicata it is often played on a zampogna or organetto, and is usually accompanied by a tamburello.

Zampogna: a type of central and southern Italian bagpipe. In Basilicata it has two chanters and two drones, with double reeds. Measured in palms, its most common sizes are 3 and 4 palms. The Lucanian variant is called 'a chiave' (keyed) because of the presence of a metal key that allows the last hole of the lower chanter to be reached. 